\title{
Global climate change and its potential impact on disease transmission by salinity-tolerant mosquito vectors in coastal zones
}

\author{
Ranjan Ramasamy ${ }^{1}$ and Sinnathamby Noble Surendran ${ }^{2}$ \\ 1 Institute of Health Sciences, Universiti Brunei Darussalam, Gadong, Brunei Darussalam \\ ${ }^{2}$ Department of Zoology, University of Jaffna, Jaffna, Sri Lanka
}

Edited by:

Rubén Bueno-Marí, University of

Valencia, Spain

Reviewed by:

Qiyong Liu, National Institute for

Communicable Disease Control and

Prevention, China

Veerle Versteirt, Institute of Tropical

Medicine, Belgium

*Correspondence:

Ranjan Ramasamy, Institute of Health

Sciences, Universiti Brunei

Darussalam, Jalan Tungku Link,

Gadong BE 1410, Brunei Darussalam

e-mail: ranjanramasamy@yahoo.co.uk
Global climate change can potentially increase the transmission of mosquito vector-borne diseases such as malaria, lymphatic filariasis, and dengue in many parts of the world. These predictions are based on the effects of changing temperature, rainfall, and humidity on mosquito breeding and survival, the more rapid development of ingested pathogens in mosquitoes and the more frequent blood feeds at moderately higher ambient temperatures. An expansion of saline and brackish water bodies (water with $<0.5 \mathrm{ppt}$ or parts per thousand, $0.5-30 \mathrm{ppt}$ and $>30 \mathrm{ppt}$ salt are termed fresh, brackish, and saline respectively) will also take place as a result of global warming causing a rise in sea levels in coastal zones. Its possible impact on the transmission of mosquito-borne diseases has, however, not been adequately appreciated. The relevant impacts of global climate change on the transmission of mosquito-borne diseases in coastal zones are discussed with reference to the Ross-McDonald equation and modeling studies. Evidence is presented to show that an expansion of brackish water bodies in coastal zones can increase the densities of salinitytolerant mosquitoes like Anopheles sundaicus and Culex sitiens, and lead to the adaptation of fresh water mosquito vectors like Anopheles culicifacies, Anopheles stephensi, Aedes aegypti, and Aedes albopictus to salinity. Rising sea levels may therefore act synergistically with global climate change to increase the transmission of mosquito-borne diseases in coastal zones. Greater attention therefore needs to be devoted to monitoring disease incidence and preimaginal development of vector mosquitoes in artificial and natural coastal brackish/saline habitats. It is important that national and international health agencies are aware of the increased risk of mosquito-borne diseases in coastal zones and develop preventive and mitigating strategies. Application of appropriate counter measures can greatly reduce the potential for increased coastal transmission of mosquito-borne diseases consequent to climate change and a rise in sea levels. It is proposed that the Jaffna peninsula in Sri Lanka may be a useful case study for the impact of rising sea levels on mosquito vectors in tropical coasts.

Keywords: Aedes, Anopheles, brackish water habitats, climate change, coastal zones, mosquito-borne diseases, preimaginal development, sea level rise

\section{INTRODUCTION}

Mosquito vectors transmit important human parasitic and arboviral diseases. Malaria caused by protozoan parasites of the genus Plasmodium, and lymphatic filariasis caused by the nematodes Wuchereria bancrofti and Brugia malayi, have been estimated to have a recent worldwide prevalence of 247 and 120 million cases respectively (World Health Organization, 2010a,b). Dengue, the most common human arboviral disease, is reported to have a prevalence of 50 million cases in more than 100 countries, with about 500,000 persons requiring hospitalization each year for dengue hemorrhagic fever/dengue shock syndrome that has overall case fatality rate of 2.5\% (World Health Organization, 2009a). Minimizing human-mosquito contact and reducing vector populations by the application of insecticides and through managing and eliminating preimaginal development sites are important components of mosquito-borne disease control programs. Reducing human - mosquito contact indoors through the use of bed nets, particularly insecticide impregnated bed nets, has successfully helped reduce malaria prevalence over the past decade in many afflicted countries (World Health Organization, 2011). However this preventive measure is less effective against dengue because the Aedes vectors of dengue, unlike important Anopheles malaria vectors, tend to bite outdoors and during daytime. Reducing vector density by eliminating or managing preimaginal development habitats, larviciding, and space and residual spraying near infection foci are therefore central to the control of Aedes aegypti and Ae. albopictus, the principal vectors of dengue (World Health Organization, 2009b).

Ongoing global changes attributable to human activities, e.g., changes in climate, healthcare, land use, pollution, population 
movements, and urbanization, can significantly alter the rates of transmission of mosquito-borne diseases in most parts of the world (Sutherst, 2004). The United Nations Framework Convention on Climate Change (UNFCCC) described global climate change as long term changes in commonly measured meteorological parameters, over and above natural variations, that are directly or indirectly attributable to human activity altering the atmospheric composition. Climate change parameters most often considered for their impact on mosquitoes are temperature, rainfall, and humidity, but others such as atmospheric particle pollution and wind can also have an impact. Primary changes in such parameters, caused principally through the increased emission of greenhouse gases into the atmosphere, can alter the bionomics of mosquito vectors and therefore the rates of transmission of mosquito-borne diseases (Sutherst, 2004 and see Dynamics of Disease Transmission by Vector Mosquitoes in the Context of Global Climate Change in Coastal Zones below). These primary changes in global climate can produce further alterations in the biosphere and geosphere that can additionally affect mosquito vector bionomics. Prominent among such secondary changes are the global distribution and characteristics of plants and animals, the frequency and severity of extreme weather events, and a global rise in sea levels. Many studies have examined the impacts of global climate change involving temperature, rainfall, and humidity on common mosquito-borne diseases like malaria and dengue (Lindsay and Martens, 1998; Githeko et al., 2000; Rogers and Randolph, 2000; Reiter, 2001; Hunter, 2003; McMichael et al., 2006; Confalonieri et al., 2007; Paaijmans et al., 2009). However, they did not consider the possible impacts of rising sea levels due to global warming on mosquito-borne disease in coastal zones. We recently proposed that a rise in sea levels can increase the prevalence of many vector-borne diseases in coastal zones (Ramasamy and Surendran, 2011).

A precise definition of the landward boundary of a coastal zone is not possible as this will depend on local characteristics. The island of Sri Lanka legislatively regards it to extend $300 \mathrm{~m}$ inland from the mean high water level. For the purpose of this article, the coastal zone is considered to be the land area extending inland from the sea-land interface where sea water salinity has a significant influence on its biological and physical characteristics. In this article we provide an overview of the possible effects of global climate change and rising sea levels on mosquito-borne diseases in coastal zones, with dengue and malaria as particular examples. It is expected that this will stimulate further consideration of a hitherto neglected aspect of global climate change and human health, and lead to the development of appropriate mitigating measures worldwide.

\section{DYNAMICS OF DISEASE TRANSMISSION BY VECTOR MOSOUITOES IN THE CONTEXT OF GLOBAL CLIMATE CHANGE IN COASTAL ZONES}

The rate of spread of a mosquito-borne disease in a nonimmune population can be represented in a simple form by the Ross-MacDonald equation (MacDonald, 1957).

$R_{o}=\frac{m a^{2} \alpha \beta p^{n}}{r\left[-\log _{\mathrm{e}}(p)\right]}$ where $R_{o}$ is the number of secondarily infections generated from a single infected human in a non-immune population

$m=$ ratio of the number of vector mosquitoes to the number of humans

$a=$ average number of human blood meals taken by a mosquito in a day

$\alpha=$ probability of transmission of pathogen from an infected human to a biting mosquito

$\beta=$ probability of transmission of pathogen from an infected mosquito to a non-immune human during feeding

$p=$ daily probability of survival of the mosquito vector

$n=$ duration in days from infection of a biting mosquito until the mosquito becomes capable of infecting humans after the pathogen undergoes obligatory development in the mosquito. This is also termed the extrinsic incubation period

$r=$ recovery rate in humans (inverse of the average duration of infectiousness in days)

The Ross-McDonald formula is fundamentally important for determining the effects of climate change on the transmission of mosquito-borne diseases in coastal and inland areas. A qualitative analysis may be made by considering the impact of the predicted changes on parameters that determine $R_{o}$.

\section{TEMPERATURE}

Adult and preimaginal forms of mosquitoes have an optimal range of temperature for survival and development and this closely matches the climate where each vector species is found. A change in the ambient temperature will tend to affect $p$. Mosquito survival in areas with less than optimal temperatures will be increased if climate change results in warming to temperatures closer the optimum for the mosquito species concerned. Thus a mosquito vector whose optimal survival temperatures are found in lowland areas of the tropics may spread to higher latitudes of the sub-tropical and temperate zones and to the higher altitudes in tropical countries. It has been suggested that a latitudinal range of shift of about $200 \mathrm{~km}$ is possible per ${ }^{\circ} \mathrm{C}$ rise in global temperature (Sutherst, 2004). A limited rise in temperature will also favor an increase in the human biting rate $a$, hasten mosquito development and therefore increase the relative vector density $m$, and reduce the extrinsic incubation period $n$ (Lindsay and Birley, 1996). Because of the exponential relationship of the extrinsic incubation period $n$ to $R_{o}$, it is a dominant variable determining $R_{o}$. However, the dependence of mosquito survival and development, human biting rates and the extrinsic incubation period on temperature is likely to show different optima for each of the parameters, which in turn will generate a complex variation of $R_{o}$ with changes in ambient temperature. The impacts of global temperature change on disease transmission by mosquito vectors are likely to be broadly similar in coastal and inland areas.

\section{RAINFALL AND HUMIDITY}

Climate change alters rainfall which has a direct effect on humidity. An optimal humidity significantly increases mosquito survival p. Furthermore, rainfall, rate of evaporation, and humidity will influence the availability of habitats for oviposition and preimaginal development of the mosquito vectors and therefore influence 
$m$, the ratio of mosquitoes to humans. An expansion of habitats for preimaginal development as a result of climate change will therefore tend to increase vector density in relation to the human population, favoring disease transmission. However the relationship between rainfall and mosquito larval habitats is a complex one. Peak malaria transmission closely follows the rainy season in tropical countries, e.g., Sri Lanka (Ramasamy et al., 1992a,b). Rainfall forms surface pools of fresh water that are favored preimaginal development habitats for the major fresh water Anopheles vectors in Sri Lanka and other tropical countries (Ramasamy et al., 1992a,b; Surendran and Ramasamy, 2010). However, excessive rainfall can wash away larvae and eggs and reduce the numbers of small puddles thereby temporarily lowering the rates of malaria transmission. Less than normal rainfall in tropical wet zones results in the drying up of rivers and formation of pools in river beds which can also increase malaria transmission. Aedes aegypti, the principal urban vector of dengue, can develop indoors in water containers, and its development is therefore less dependent on rainfall (Barraud, 1934; World Health Organization, 2009b). Aedes albopictus, the alternative vector of dengue in mainly peri-urban and rural settings, tends to undergo larval development in water collections outdoors and is therefore more dependent on rain-fed habitats, e.g., water collections in leaf axils, tree holes, and discarded containers (Barraud, 1934; World Health Organization, 2009b). Aedes albopictus densities increase during the monsoon season in the Jaffna peninsula, a coastal zone in Sri Lanka (Surendran et al., 2007a).

Coastal zones, depending on their aridity, are likely to be affected similarly to inland areas by rainfall. However, an additional consideration in coastal areas is that a drier climate can favor salinity-tolerant vectors, e.g., Anopheles sundaicus in Southeast Asia and An. merus and An. melas in Africa. Conversely, higher rainfall can expand the habitats of fresh water vectors like An. culicifacies and An. gambiae in the coastal zones of Asia and Africa respectively. Alterations in vector composition as discussed in Section "Variations in Mosquito and Pathogen Populations" can influence disease transmission rates.

\section{VARIATIONS IN MOSOUITO AND PATHOGEN POPULATIONS}

The variables $\alpha$ and $\beta$ in the Ross-MacDonald equation are dependent partly on the intrinsic genetic characteristics of the vector. The innate immune mechanisms in the midgut that prevent infection of the gut and further development of the pathogen are genetically determined. The subsequent ability of pathogens to disseminate through the hemocoele to the salivary glands and then be transmitted to humans during a blood meal is also influenced by genetic factors. Therefore $\alpha$ and $\beta$ will vary with vector species and pathogen strain. Both factors contribute to vector competence, which is a measure of the intrinsic ability of a particular species of vector to transmit disease.

The strain of pathogen can also influence $\alpha$ and $\beta$ and thereby alter $R_{o}$. The replacement of a local strain of dengue virus III subtype by a more virulent III subtype in Sri Lanka in the 1980s increased the incidence of dengue hemorrhagic fever. Although both dengue III strains multiplied equally well in cultured cell lines, and infected an equal proportion of mosquitoes, the virulent strain of the virus multiplied to higher titers and disseminated to the salivary glands more efficiently than the local strain (Hanley et al., 2008). These findings are consistent with the two viral strains possessing the same $\alpha$ but different $\beta$ values. Global climate change therefore can potentially influence $\alpha$ and $\beta$ by causing changes in vector populations and pathogen strains that are better adapted to the altered climate.

The implications of these considerations for coastal zones are that changes in vector composition as a result of alterations in the extent and salinity of larval habitats can modify disease transmission dynamics. Furthermore, genetic changes in pathogens that result in better adaptation to salinity-tolerant mosquitoes can increase disease transmission rates in coastal areas.

\section{HUMAN IMMUNITY}

A population exposed to a mosquito-borne disease will over time generate protective immune responses to the pathogen that can result in complete or partial immunity to reinfection. Near complete immunity may develop against a particular dengue virus serotype (Guzman and Vazquez, 2010) while partial immunity resulting in milder disease is more characteristic of malaria (Ramasamy, 1998). Either partial or complete immunity will alter the recovery rate $r$ and effectively reduce $\beta$ in the Ross-MacDonald equation. Individuals in malaria-endemic areas develop antibodies to the surface antigens on gametes that develop in the mosquito midgut from ingested gametocytes and these are able to reduce the infectivity of the parasite to mosquitoes (Peiris et al., 1988). This phenomenon, termed transmission blocking immunity, tends to reduce the value of $\alpha$ and consequently $R_{o}$ in malaria-endemic areas. However it has also been observed that antibodies to the sexual stages of malaria parasites, depending on their concentration, sometimes have the opposite effect, i.e., they enhance transmission to mosquitoes (Peiris et al., 1988). Therefore immunity, and its qualitative and quantitative aspects as well as its temporal change in the population, introduces considerable complexity into modeling disease transmission. Generally, the expansion of vector populations, as a result of climate change, into disease-free areas or areas where disease endemicity is insufficient to elicit good protective immunity, will often lead to initial high rates of disease transmission that will decrease in time as the population develops immunity. Similar considerations on population immunity apply to the transmission of mosquito-borne diseases in coastal zones.

\section{MODELED PREDICTIONS ON THE IMPACTS OF PRIMARY GLOBAL CLIMATE CHANGE ON MOSQUITO-BORNE DISEASES}

Models have been developed for forecasting the impact of global climate change on mosquito-borne diseases, notably the global distributions of malaria (Lindsay and Martens, 1998; Githeko et al., 2000; Rogers and Randolph, 2000; Paaijmans et al., 2009) and dengue (Hales et al., 2002). One model used current temperature, rainfall, and humidity ranges that permit malaria transmission to forecast malaria distribution in 2050 in a global climate change scenario (Rogers and Randolph, 2000). This model found surprisingly few changes, but predicted that some parts of the world that are presently free of malaria may be prone to a greater risk of malaria transmission while certain malaria-endemic areas 
will have a decreased risk of malaria transmission (Rogers and Randolph, 2000). Larger areas of northern and eastern Australia are expected to become more conducive for the transmission of dengue (McMichael et al., 2006) and a greater proportion of the global population at risk of dengue (Hales et al., 2002) as a result of global climate change. While these models did not specifically address changes in coastal zones, the transmission of malaria (Rogers and Randolph, 2000) and dengue (Hales et al., 2002; McMichael et al., 2006) were generally predicted to increase in coastal areas of northern and eastern Australia. Many modeling forecasts are limited by uncertainties in the extent of global climate change as a result of the inability to accurately predict major drivers such as future emission rates of greenhouse gases. Other factors such as the resilience of the geosphere and biosphere that are difficult to estimate precisely, and regional characteristics, can also influence climate change parameters. Furthermore, the considerable adaptability of mosquito vectors and their pathogens to changing environments are difficult to model. Models however have an important role in highlighting potential problems and the need to develop measures to counter possible increases in disease transmission.

Global climate change has led to observable alterations in the global distribution of plants and animals with species adapted to warmer temperatures moving to higher latitudes (Root et al., 2003). However there is no unequivocal evidence yet that global climate change has already affected the distribution of a mosquitoborne disease in inland or coastal areas. The reports of increased incidence of malaria epidemics related to warmer temperatures in the Kenyan highlands have been controversial as changes in many other factors could have influenced malaria transmission in this area, and perhaps even masked an increase in transmission due to higher temperatures (Githeko et al., 2000; Alonso et al., 2011; Omumbo et al., 2011; Chaves et al., 2012). However it is clear that the incidence of malaria has decreased over the last decade in many countries due primarily to better case detection and treatment, the use of insecticide treated mosquito nets and indoor residual spraying of more effective insecticides (World Health Organization, 2011). It seems quite likely that such improvements in malaria control measures worldwide have masked any tendency for the incidence of malaria to increase as a result of global climate change (Gething et al., 2010).

On the other hand, there is evidence that short term changes in global climate can influence the incidence of mosquito-borne diseases. The El-Nino Southern Oscillation (ENSO) entails multiannual cyclic changes in the temperature of the eastern Pacific Ocean that influences air temperature and rainfall in large areas of the bordering continents, spreading as far as Africa. ENSO has been associated with a higher incidence of dengue in some countries, notably in parts of Thailand in recent times (Tipayamongkholgul et al., 2009). Global warming due to the greenhouse effect may increase the frequency of ENSO events (Timmermann et al., 1999) and therefore cause more numerous epidemics of dengue. The warming of surface sea temperatures in the western Indian Ocean due to short term fluctuations known as the Indian Ocean Dipole (IOD) is associated with higher malaria incidence in the western Kenyan highlands (Hashizume et al., 2009). The effects of short term ENSO and IOD events are a likely indication of the potential impacts of long term global climate change on mosquito-borne diseases that can also affect coastal zones.

There have been very few studies on other primary climate changes like wind and atmospheric pollution that can also affect mosquito populations in coastal areas. Changes in wind patterns as a result of climate change are difficult to predict and likely to be locality-specific. It can be expected that higher onshore wind velocities will tend to disperse mosquito populations further inland. Atmospheric pollution will be higher in the vicinity of urban coastal areas, and it may be anticipated that mosquitoes will adapt to pollution with time. The gaps in knowledge in these areas need to be addressed.

\section{EFFECTS OF SECONDARY CHANGES ON THE TRANSMISSION OF MOSOUITO - BORNE DISEASES IN COASTAL AREAS}

The more important secondary changes caused by climate change that can influence disease transmission in coastal areas are alterations in the distribution and types of plants and animals, and a rise in sea levels. The frequency and severity of extreme weather events will affect coastal zones but their impact on mosquitoborne disease transmission is generally likely to be short-lived. The possible impact of a rise in sea levels is considered in Section "Rising Sea Levels Due to Global Warming Can also Influence the Transmission of Mosquito-Borne Diseases in Coastal Zones." The nature and type of vegetation is related to the availability of larval habitats. A measure of vegetation that can be assessed by remote sensing light reflectance is the Normalized Difference Vegetation Index (NVDI). A recent study in Paraguay that measured forest cover over a period of time by the NVDI showed that the incidence of malaria was associated with deforestation (Wayant et al., 2010). Vegetation associated with water, e.g., rice fields, are positively correlated with larval habitats and this has for example been demonstrated by recent remote sensing studies in Burkina Faso (Dambach et al., 2009). NVDI measurements also showed a positive correlation between vegetation and anopheline larval density in a coastal town in Kenya (Eisele et al., 2003). These findings suggest by analogy that changes in the nature and types of vegetation in coastal zones, as a result of climate change, can influence the transmission of malaria and most likely other mosquito-borne diseases. Changes in vegetation and agricultural practices driven by climate change can affect the prevalence and distribution of wild animals and livestock that provide alternatives to humans as sources of blood meals for mosquitoes. This can also influence the transmission of mosquito-borne diseases in coastal zones.

A case study from Guyana involving a malaria epidemic in the 1950s illustrates the complex interactions between some of these factors on malaria transmission in a coastal zone (Giglioli, 1963). Anopheles darlingi, an anthropophagic (females preferring to feed on human blood) and endophilic (preferring to rest indoors) freshwater species, was the primary malaria vector in the Demerara river estuary in Guyana. It was eliminated, together with malaria, in the estuary by an indoor DDT spraying campaign in 1946-1950. The salinity-tolerant, zoophagic (preferring to feed on animal blood) and exophilic (preferring to rest outdoors) An. aquasalis was a minor vector in the estuary, but increased in numbers during dry seasons due to saline water intrusion in the estuary. The elimination of An. darlingi in the area was accompanied by the 
conversion of pastures into rice fields, and increased human settlement. An outbreak of Plasmodium vivax malaria that occurred in 1960-1961 was accompanied by a marked increase in An. aquasalis collection indoors. The evidence suggested that there were two main causes for these changes, viz. adaptation of An. aquasalis to become more anthropophagic and endophilic as a result of diminishing numbers of livestock and an increase in the human population density, and the immigration of infected persons into the area. These changes were sufficient to re-establish endogenous malaria transmission (Giglioli, 1963).

\section{RISING SEA LEVELS DUE TO GLOBAL WARMING CAN ALSO INFLUENCE THE TRANSMISSION OF MOSOUITO-BORNE DISEASES IN COASTAL ZONES}

Approximately 5\% of mosquito species are adapted to undergo preimaginal development in brackish and saline waters (water with $<0.5$ ppt or parts per thousand, $0.5-30$ and $>30$ ppt salt are termed fresh, brackish, and saline respectively). Many salinitytolerant mosquitoes are important vectors of human diseases as shown in Table 1.

Salinity-tolerant mosquito larvae possess cuticles that are less permeable to water than freshwater forms, and their pupae have thickened and sclerotized cuticles that are impermeable to water and ions (Bradley, 1987). Salinity-tolerant mosquito larvae also possess varying physiological mechanisms to cope with salinity. Aedes taeniorhynchus drink the surrounding fluid and excrete $\mathrm{Na}^{+}$and $\mathrm{Cl}^{-}$from the posterior rectum to produce hyperosmotic urine (Bradley, 1987). Culex tarsalis larvae accumulate proline and trehalose in hemolymph to maintain isoosmolarity in brackish waters in a process termed osmoconformation (Garrett and Bradley, 1987). Anopheles albimanus larvae are able to differentially localize sodium-potassium ATPase in rectal cells in fresh or saline water for osmoregulation through ion excretion (Smith et al., 2008).

We hypothesize that mosquito-borne disease transmission in coastal areas are not only influenced by global climate change causing alterations in temperature, rainfall, and humidity, but also rising sea levels (Ramasamy and Surendran, 2011). The
Intergovernmental Panel for Climate Change has predicted that global warming will raise sea levels by $18-59 \mathrm{~cm}$ by the end of the twenty-first century through the melting of glaciers and polar ice as well as the thermal expansion of seawater (Nicholls et al., 2007; United Nations Intergovernmental Panel on Climate Change, 2007). Rising sea levels will affect the extent of saline or brackish coastal water bodies including estuaries, lagoons, marshes, and mangroves that provide preimaginal development sites for salinity-tolerant mosquito species in coastal areas. Models suggest that the salinity of estuarine systems will rise and their boundaries move further inland with more pronounced tidal water flows into rivers (Nicholls et al., 2007). A proportion of coastal wetlands such as salt marshes and mangroves will become inundated by the sea but this will be compensated for by additional saline wetlands being formed further inland (Nicholls et al., 2007). Rising sea levels, and higher water withdrawal rates from freshwater aquifers near the coast by expanding populations will increase saltwater intrusion in the aquifers (Food and Agricultural Organisation, 2007). These changes in turn will cause ponds, lakes, and wells in coastal areas to become more brackish. The potential impact of rising sea levels, as opposed to climate change involving temperature, rainfall, and humidity, on the prevalence of mosquito-borne diseases in coastal areas was not recognized (Lindsay and Martens, 1998; Githeko et al., 2000; Rogers and Randolph, 2000; Reiter, 2001; Hunter, 2003; McMichael et al., 2006; Confalonieri et al., 2007; Paaijmans et al., 2009), until we proposed that an expansion of brackish and saline water bodies in coastal areas due to rising sea levels can increase the density of salinity-tolerant mosquito vectors and cause freshwater mosquito vectors to adapt to brackish water habitats (Ramasamy and Surendran, 2011). Such developments can lead to an increase in the density of vectors relative to humans ( $m$ in the Ross-MacDonald equation, see Dynamics of Disease Transmission by Vector Mosquitoes in the Context of Global Climate Change in Coastal Zones) and therefore to an increase in $R_{o}$. Increased transmission of mosquito-borne diseases in coastal areas due to salinity-tolerant vectors can also cause the diseases to be propagated to inland areas through bridging vectors that may be fresh water or euryhaline (possessing the ability to undergo

Table 1 | Common salinity-tolerant mosquito vectors of human disease adapted with permission from Ramasamy and Surendran (2011).

\begin{tabular}{|c|c|c|}
\hline Species & Distribution & Transmitted pathogens \\
\hline Aedes dorsalis & Temperate Eurasia, N America & West Nile virus and Western equine encephalitis virus \\
\hline Ae. (Ochlerotatus) taeniorhynchus & N \& S America & Eastern equine encephalitis virus \\
\hline Ae. togoi & North Pacific rim & Japanese encephalitis virus and filarial parasites \\
\hline Ae. (Ochlerotatus) vigilax & Australasia, SE Asia & Filarial parasites, Ross River virus, Barmah forest virus \\
\hline Anopheles albimanus and An. aquasalis & N \& S America, Caribbean & Malaria parasites \\
\hline An. atroparvus & Coast of W Europe & Malaria parasites \\
\hline An. farauti and An. annulipes & Australasia & Malaria parasites \\
\hline An. melas and An. merus & Africa & Malaria parasites \\
\hline An. multicolor & N Africa, Middle East & Malaria parasites \\
\hline An. sacharovi & Russia, S Europe & Malaria parasites \\
\hline An. subpictus & Asia & Malaria and filarial parasites \\
\hline An. sundaicus & S Asia, SE Asia, China & Malaria parasites \\
\hline Culex sitiens & Indian ocean rim countries & Japanese encephalitis virus and Ross River virus \\
\hline Cx. tritaeniorhynchus & Russia, Middle East, Africa, India & Japanese encephalitis virus \\
\hline
\end{tabular}


preimaginal development over a wide range of salinity) species. On the other hand, it is possible that rising salinity in coastal habitats, where important fresh water mosquitoes undergo preimaginal development, may reduce disease transmission. However, as discussed below, fresh water mosquitoes are capable of adapting to an expansion of brackish water habitats in coastal areas.

There is very good historical evidence that changes in the extent of brackish water coastal habitats of anopheline mosquitoes has influenced the distribution of malaria. The association of malaria with the Pontine Marshes near Rome is one such example. Draining of the marshes in the early twentieth century with water pumps had greatly reduced malaria incidence. The flooding of the marshes with sea water toward the end of World War 2 was accompanied by a resurgence of malaria which was reversed once again by draining the marshes (Geissler and Guillemin, 2010). A reduction in the extent of the habitat of a brackish water vector has also historically been associated with a lower incidence of malaria in England and the Netherlands. An. atroparvus was primarily responsible for transmitting vivax malaria until the early 1900s in marshland areas of England (Dobson, 1994) and the river deltas of the Netherlands (Takken et al., 2002). A reduction of the breeding sites for An. atroparvus as a result of the draining of coastal marshes helped eliminate malaria from these areas (Dobson, 1994; Takken et al., 2002).

Because of the slow rate of rise in sea levels due to global warming, and confounding factors such as improvements in disease prevention and treatment, it has not yet been possible to observe an impact of rising sea levels on mosquito vectors and their transmitted diseases. However the December 2004 Asian tsunami provided relevant examples that suggest that such effects can indeed occur. The density of An. sundaicus s.l., a widespread malaria vector along Asian coasts (Surendran et al., 2010; Sinka et al., 2011), increased in the Andaman and Nicobar islands following the intrusion of sea water inland, and this was accompanied by a rise in the incidence of falciparum malaria in the islands (Krishnamoorthy et al., 2005). Higher densities of Culex sitiens, an established vector of arboviruses (Weaver and Reisen, 2010), and An. sundaicus s.l. were also observed in an area of Thailand that was affected by the tsunami (Komalamisra et al., 2006). New brackish water habitats that were created by the tsunami led to freshwater breeding mosquitoes adapting to undergo preimaginal development in them, e.g., larvae of typical freshwater mosquitoes An. stephensi and An. culicifacies, were found in newly formed brackish water bodies immediately after the 2004 tsunami in India (Gunasekaran et al., 2005). An. culicifacies larvae were also observed for the first time in brackish water bodies near the coast in eastern Sri Lanka, 5 years after the tsunami although a relationship to the inundation caused by the tsunami could not be established (Jude et al., 2010). Mosquitoes are highly adaptable as shown by their ability to exploit a variety of ecological niches and rapidly develop insecticide resistance. It is therefore likely that, given adequate selective pressure most, if not all, fresh water mosquito vector species can adapt to oviposit and undergo preimaginal development in brackish water.

Human-induced ecological changes provide additional examples that suggest that an expansion of brackish water mosquito habitats can increase malaria transmission. Large-scale shrimp farming in the Mekong delta of Vietnam locally increased the density of An. sundaicus s.l. (Trung et al., 2004) and similar trends have been seen elsewhere in Southeast Asia. Also, higher densities of Aedes (Ochlerotatus) camptorhynchus, a known vector of Ross River virus, have been associated with increasing salinization of freshwater bodies caused by large-scale and intensive wheat farming in Western Australia (Jardine et al., 2008; Carver et al., 2009, 2010; van Schie et al., 2009).

\section{AEDES AEGYPTI AND AEDES ALBOPICTUS, THE MAJOR VECTORS OF DENGUE, CAN UNDERGO PREIMAGINAL DEVELOPMENT IN BRACKISH WATER}

Development of a vaccine against dengue is hampered by the existence of four virus serotypes and because a suboptimal immune response to any one of the serotypes can exacerbate disease caused by a subsequent infection with that serotype (Halstead, 2003; Chun et al., 2007). Only drugs that provide symptomatic relief are presently available to treat dengue and therefore there is considerable concern internationally about the currently observed global spread of dengue, chikungunya, and other arboviral diseases (Cavrini et al., 2009; Schwartz and Albert, 2010; Weaver and Reisen, 2010). Hence the control of mosquito vector populations is crucial for reducing dengue and arboviral diseases for which vaccines are not available.

Aedes aegypti is the principal tropical mosquito vector of arboviruses causing yellow fever, dengue, and chikungunya (Cavrini et al., 2009; Weaver and Reisen, 2010; Walter Reed Biosystematics Unit, 2011). Ae. aegypti is also able to transmit other arboviruses, including Ross River and Murray Valley Encephalitis viruses, in laboratory experiments (Ramasamy et al., 1990), and is a natural vector of B. malayi that causes filariasis in Asia (Erickson et al., 2009). The closely related Ae. albopictus is an alternate vector of dengue and chikungunya (Rezza et al., 2007; Cavrini et al., 2009; Weaver and Reisen, 2010; Walter Reed Biosystematics Unit, 2011). Unlike Ae. aegypti, Ae. albopictus has developed a diapausing egg stage that has enabled it to survive winters and spread to temperate regions, causing for example a chikungunya epidemic in northern Italy in 2007 (Rezza et al., 2007) and two autochthonous cases of dengue in southern France in 2010 (La Ruche et al., 2010).

Importantly, larval source management and reduction strategies are presently directed exclusively toward freshwater habitats, because of the long and widely held view that the two Aedes species only develop naturally in fresh water (Barraud, 1934; Chan et al., 1971; Kulatilaka and Jayakuru, 1998; Ooi et al., 2006; World Health Organization, 2009a,b). We recently showed however that Ae. aegypti and Ae. albopictus are able to oviposit and undergo preimaginal development in collections of brackish water in unused wells, abandoned boats, disposable plastic, and glass food and beverage containers (Figure 1) in coastal Sri Lanka (Figure 2) and Brunei Darussalam (Ramasamy et al., 2011). We hypothesized that brackish water development may be an adaptive response to the almost exclusive application of Aedes larvae control measures (with insecticides such as temephos and Bacillus thuringiensis toxin) to freshwater habitats and the elimination of such habitats in the urban and peri-urban environment (Ramasamy et al., 2011). Furthermore, the brackish water Ae. aegypti larval sites were found close to areas of high dengue incidence in the city of Jaffna 


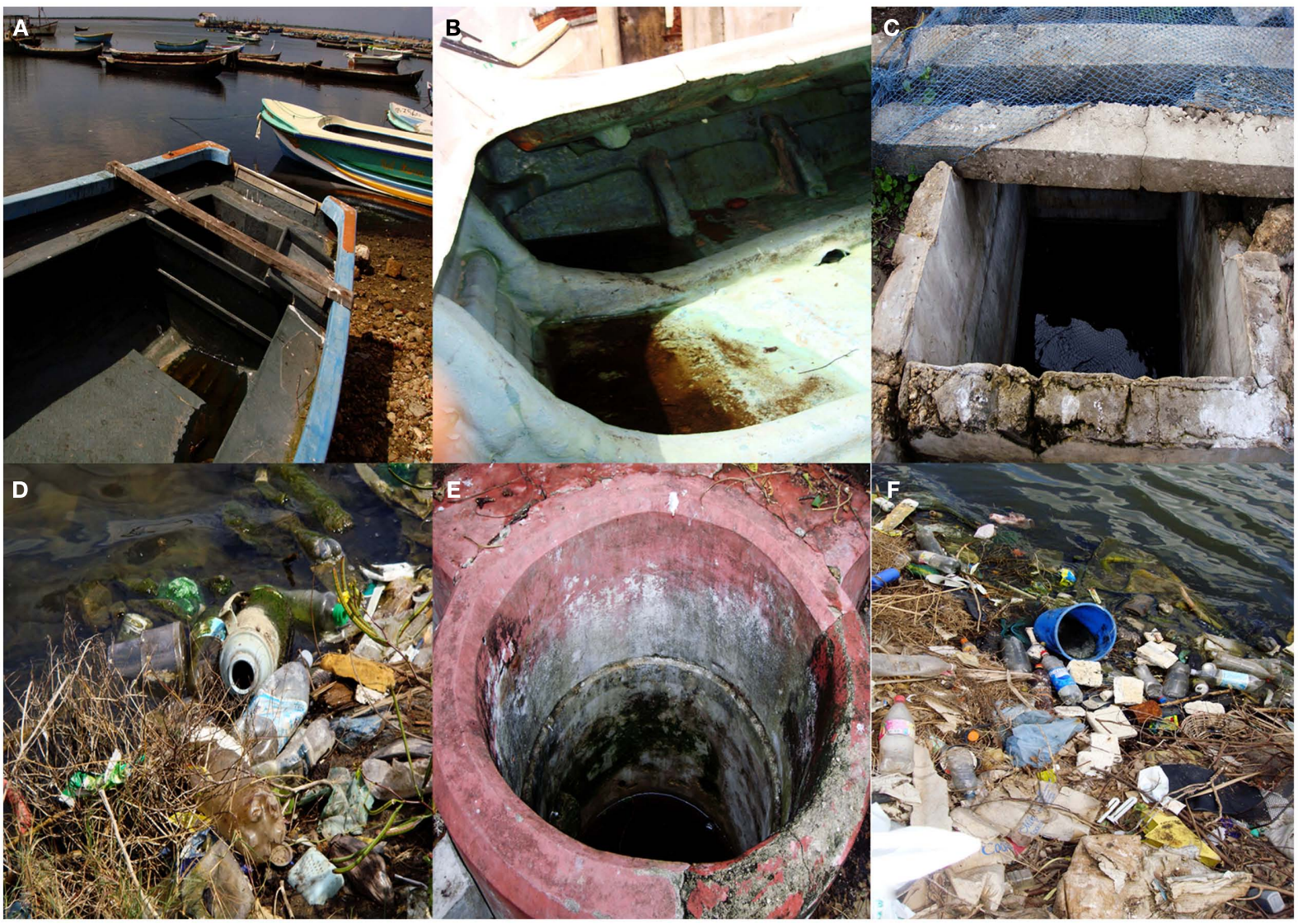

FIGURE 1 | Brackish water development habitats of Ae. aegypti and Ae. albopictus larvae in Sri Lanka. The photographs show the brackish water collections containing larvae in: $(\mathbf{A}, \mathbf{B})$ - disused boats; (C,E): abandoned wells; (D,F) discarded food and beverage containers (reproduced with permission from Ramasamy et al., 2011). in the Jaffna peninsula of northern Sri Lanka (Figures 2 and 3) suggesting that they may play a role in the transmission of dengue in coastal zones (Ramasamy et al., 2011). In a limited survey of domestic brackish water wells in a coastal division of Jaffna city, $\sim 25 \%$ of brackish water wells $(n=110)$ were found to have Ae. aegypti larvae (Surendran, S. N., Jude, P. J., Thabothini, V., Raveendran, S., Ramasamy, R., unpublished data). Household wells are usually exempt from dengue control measures because they are not considered to be significant preimaginal development sites (World Health Organization, 2009b). Our findings are the first to show that brackish water domestic wells are a habitat for the development of mosquito vectors of dengue. The Aedes larval positivity rates in brackish water we recorded in Sri Lanka are higher than the House Index (\% of houses positive for Aedes larvae) or Breteau Index (number of containers with larvae per 100 houses) for fresh water habitats that have been typically associated with dengue epidemics elsewhere (Sanchez et al., 2006). We therefore hypothesize that the Aedes mosquitoes emerging from such hitherto unrecognized habitats, that are not targeted by larval source reduction programs, may at least be partly responsible for the failure to eliminate dengue in Sri Lanka and other island states like Singapore and Cuba where the dengue control programs exclusively target fresh water larval habitats (Chan et al., 1971; Kulatilaka and
Jayakuru, 1998; Ooi et al., 2006; Sanchez et al., 2006; World Health Organization, 2009b).

We have suggested that global warming, leading to an expected $18-59 \mathrm{~cm}$ rise in sea levels by the end of this century (Nicholls et al., 2007; United Nations Intergovernmental Panel on Climate Change, 2007), and a consequent expansion of coastal brackish water habitats, can increase disease transmission by salinitytolerant Aedes vectors in coastal areas that can then spread disease to inland areas through bridging vectors (Ramasamy and Surendran, 2011; Ramasamy et al., 2011). Aedes albopictus since the 1980s has spread from Asia to Africa, America, and Europe (Rezza et al., 2007; Cavrini et al., 2009; La Ruche et al., 2010; Weaver and Reisen, 2010). We further hypothesize that salinity-tolerant and diapausing Ae. albopictus will increase the potential for disease transmission in coastal areas of the temperate zone.

\section{AEDES AEGYPTI AND AEDES ALBOPICTUS MAY BE ADAPTING TO BRACKISH WATER HABITATS}

There is evidence to suggest that the larvae of Ae. aegypti and Ae. albopictus in the Jaffna peninsula, where there is greater salinization of ground water compared to Batticaloa in mainland east Sri Lanka, are more tolerant of salinity than in Batticaloa (Ramasamy et al., 2011). These conclusions were drawn from examining the 


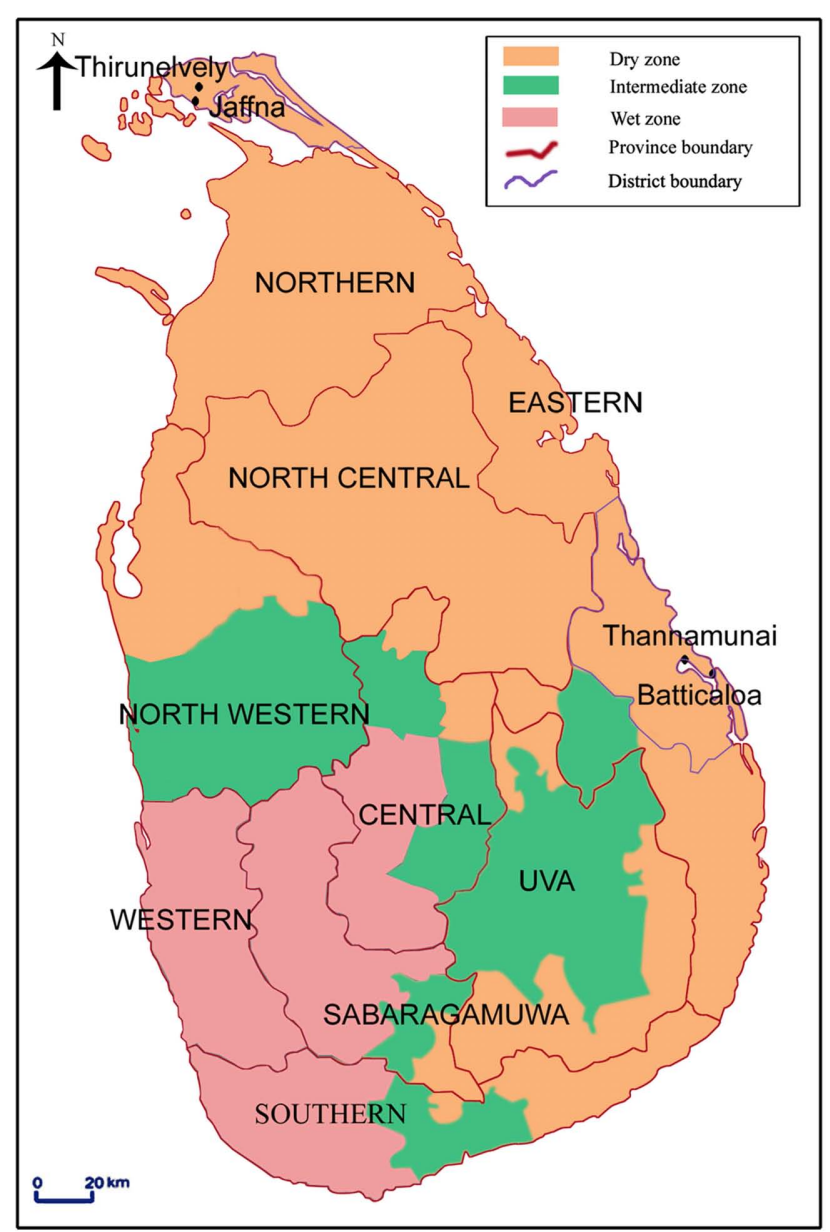

FIGURE 2 | Map of Sri Lanka showing the different provinces and the Aedes larvae collection sites in Jaffna and Batticaloa districts. Sri Lanka is an island in the Indian ocean with an area of $65525 \mathrm{~km}^{2}$ located between latitudes 5'55 and 9'50 North of the equator The central hills of the island divide the surrounding plains into two distinct rainfall zones: the wet and dry zones. The wet zone receives an annual rainfall exceeding $2500 \mathrm{~mm}$ in two main rainy seasons: the North-East monsoon in October-December and the South-West monsoon in May-July. Inter-monsoonal rains also occur in the wet zone. The dry zone, with an annual rainfall below $2000 \mathrm{~mm}$, receives maximal rainfall during the North-East monsoon and little or no rain during the rest of the year. An intermediate zone, with mixed characteristics, lies between the dry and wet the intermediate zone. The beige, green, and pink shaded areas show the dry, intermediate, and wet rainfall zones respectively (reproduced with permission from Ramasamy et al., 2011).

tolerance of first and third instar larvae, derived from eggs in freshwater ovitraps, to different salinities, with emergence of adults as the end point (Ramasamy et al., 2011). The greater salinization of ground water in Jaffna peninsula is the result of a combination of factors - its predominant limestone geology (Rajasooriyar et al., 2002), a high and increasing population density, and growing use of water from inland limestone aquifers for agriculture and domestic consumption. Rising sea levels are expected to further exacerbate ground water salinization in the relatively flat peninsula.
Aedes aegypti larvae in laboratory studies have been shown to osmoconform in the short term to a limited increase in the salinity of the surrounding fluid by accumulating ions and amino acids in their hemolymph (Edwards, 1982). There is presently no data to differentiate between such a reversible physiological mechanism and irreversible genetic changes as causes for the adaptation of $A e$. aegypti and Ae. albopictus to brackish water. If genetic changes are responsible, then it is possible that the terms $\alpha$ and $\beta$ in the RossMacDonald equation may be different between the fresh water and salinity - tolerant forms of the two vector mosquitoes, resulting in a differential capacity to transmit dengue virus. Analogous considerations also apply to malaria transmission. Variations in salinity tolerance between sibling species within the many anopheline species complexes are known (Ramasamy and Surendran, 2011; Surendran et al., 2011) and these may have different abilities to transmit malaria. The possible adaptation of An. culicifacies to brackish water in eastern Sri Lanka (Jude et al., 2010) and India (Gunasekaran et al., 2005) has been discussed in Section "Rising Sea Levels due to Global Warming can also Influence the Transmission of Mosquito-Borne Diseases in Coastal Zones." In the long term, such adaptation can lead to speciation and this is exemplified in Africa by the evolution of the salinity-tolerant coastal vectors Anopheles merus and Anopheles melas from the fresh water vector Anopheles gambiae (Coluzzi and Sabatini, 1969). Changes in the relative proportions of closely related but genetically different vector populations resulting from adaptation to an increased availability of brackish water habitats in coastal areas can therefore alter the rates of disease transmission.

\section{JAFFNA PENINSULA AS A CASE STUDY FOR THE IMPACTS OF CLIMATE CHANGE AND RISING SEA LEVELS ON MOSOUITO VECTORS IN TROPICAL COASTS}

The Jaffna peninsula is located at the apex of northern Sri Lanka (Figures $\mathbf{2}$ and 3). Jaffna is traditionally an agricultural area with an extensive coastline. It is largely composed of sedimentary limestone of the Miocene period (Rajasooriyar et al., 2002), has a maximum altitude of $10.4 \mathrm{~m}$ and contains many lagoons and other sea water inlets. Almost all locations in the peninsula are $<10 \mathrm{~km}$ from the sea, lagoon, or other sea water inlets. Therefore the entire peninsula may be considered to be a coastal zone. Open wells sunk in the limestone aquifers in Jaffna are normally recharged during the North-East monsoon rains in the months from October to December. Water from wells is used for drinking and domestic, agricultural, and industrial purposes at an increasing rate. Many areas in Jaffna city have piped fresh water derived from deep artesian wells from Thirunelvely in the center of the peninsula. However brackish water from wells in the coastal areas of the city is used for watering gardens and washing. Jaffna has a high and increasing population density estimated presently to be 700 persons per $\mathrm{km}^{2}$ in a total peninsular area of $1130 \mathrm{~km}^{2}$. Increasing salinization and nitrate pollution of ground water in the peninsula, and salinization in the outlying populated islands, is a serious problem in the Jaffna district (Nagarajah et al., 1988).

The Jaffna district has traditionally been an endemic area for malaria. There was a high incidence of malaria in the 1990s with an estimated peak of $\sim 10,000$ cases per 100,000 persons per year in 1998 (Figure 4). Population estimates for this period were not 


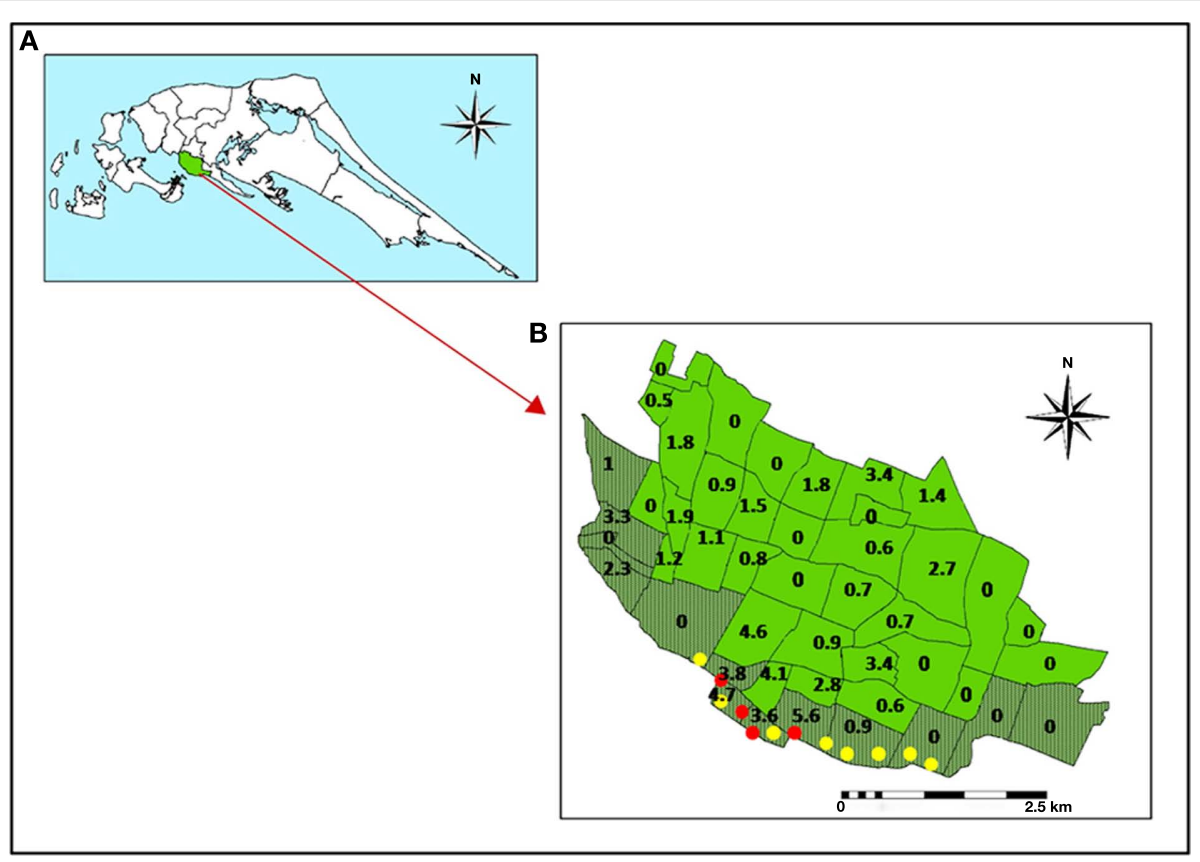

FIGURE 3 | Relationship between dengue incidence and brackish water sites with larvae of Ae. aegypti in Jaffna. (A) Map of Jaffna peninsula in northern Sri Lanka. (B) Map of Jaffna city showing its administrative divisions with coastal divisions shaded in dark green. The numbers indicate the incidence of dengue per 1000 persons for the
7 months October 2010 to April 2011 in each division. Red and yellow filled circles show brackish water sites along the Jaffna coastal area that were respectively positive and negative for Ae. aegypti larvae. Each circle had one or more container, well or boat that was sampled (reproduced with permission from Ramasamy et al., 2011). accurate due to large-scale displacement and migration caused by civil war. There was a sharp decline in malaria cases after 2002 and no local transmission has been reported since 2007. A study of land use patterns, socio-economic status, and vector breeding identified certain coastal areas to have a high risk of malaria in the peninsula (Kannathasan et al., 2009). The anopheline mosquito species distribution in cattle-baited collections in the district in 2005-2006 was An. culicifacies $0.5 \%$, An. subpictus 46\%, An. varuna 4\%, An. nigerrimus 44\%, and An. pallidus 5.5\% (Kannathasan et al., 2008). Of the three An. subpictus sibling species, B, C, and D, collected in the peninsula at the time, the more salinity-tolerant species $\mathrm{B}$ was predominant accounting for $\geq 65 \%$ of the An. subpictus collection (Kannathasan et al., 2008). It was particularly prevalent in coastal sites (Kannathasan et al., 2008). However, we have recently shown that most, if not all, An. subpictus species B identified on morphological characteristics in Sri Lanka are genetically closer to the well-known salinity-tolerant vector of Asia, An. sundaicus s.l. (Surendran et al., 2010). The results therefore suggest that the salinity-tolerant An. sundaicus s.l. has been the major vector of malaria in the Jaffna peninsula in the past, and its abundance and Plasmodium infection rates need to be monitored to prevent a recurrence of malaria.

A large number of dengue cases with several deaths have been reported in Jaffna in recent years with a peak of incidence in 2010 of 490 cases per 100,000 persons (Figure 5). Dengue transmission occurs during and soon after the North-East monsoon rains in October-December in Jaffna. The Jaffna peninsula also experienced an epidemic of chikungunya during 2006-2007 (Surendran et al., 2007b). The spread of chikungunya was rapid and resulted in much morbidity in Jaffna due possibly to the lack of prior immunity in the population. It was estimated that over 10,000 people were treated at the out-patient department of government hospitals in November-December, 2006 (Surendran et al., 2007b). Aedes aegypti and Ae. albopictus, the known vectors of dengue and chikungunya, are present in the Jaffna peninsula and are able to oviposit in indoor and outdoor ovitraps with mixed infestation throughout the year (Surendran et al., 2007a). There was a seasonal variation in the prevalence of the two mosquito species, with Ae. aegypti predominating during the pre-monsoon period and Ae. albopictus during the monsoon (Surendran et al., 2007a).

There are no reports on the local transmission of Japanese encephalitis and filariasis in the Jaffna peninsula in recent times although the respective primary vectors Culex tritaeniorhynchus and Culex quinquefasciatus are present (Rajendram and Antony, 1991). Furthermore, larvae of Culex sitiens, a known vector of arboviruses including the Japanese encephalitis virus, were collected from domestic wells with salinity ranging from 10 to $20 \mathrm{ppt}$ in the islands off the peninsula (Surendran, S.N., unpublished observations).

The major malaria control activities in the peninsula involve the early detection of cases and prompt treatment, indoor residual spraying of insecticides, and the supply of insecticide treated bed nets to the population. For the control of dengue, an active source reduction campaign along with public education and focal thermal fogging are undertaken by health authorities in Jaffna. A study carried out during the 2006 chikungunya epidemic in Jaffna targeting 162 families revealed that although they were generally aware of the involvement of mosquitoes in the transmission of the disease, 

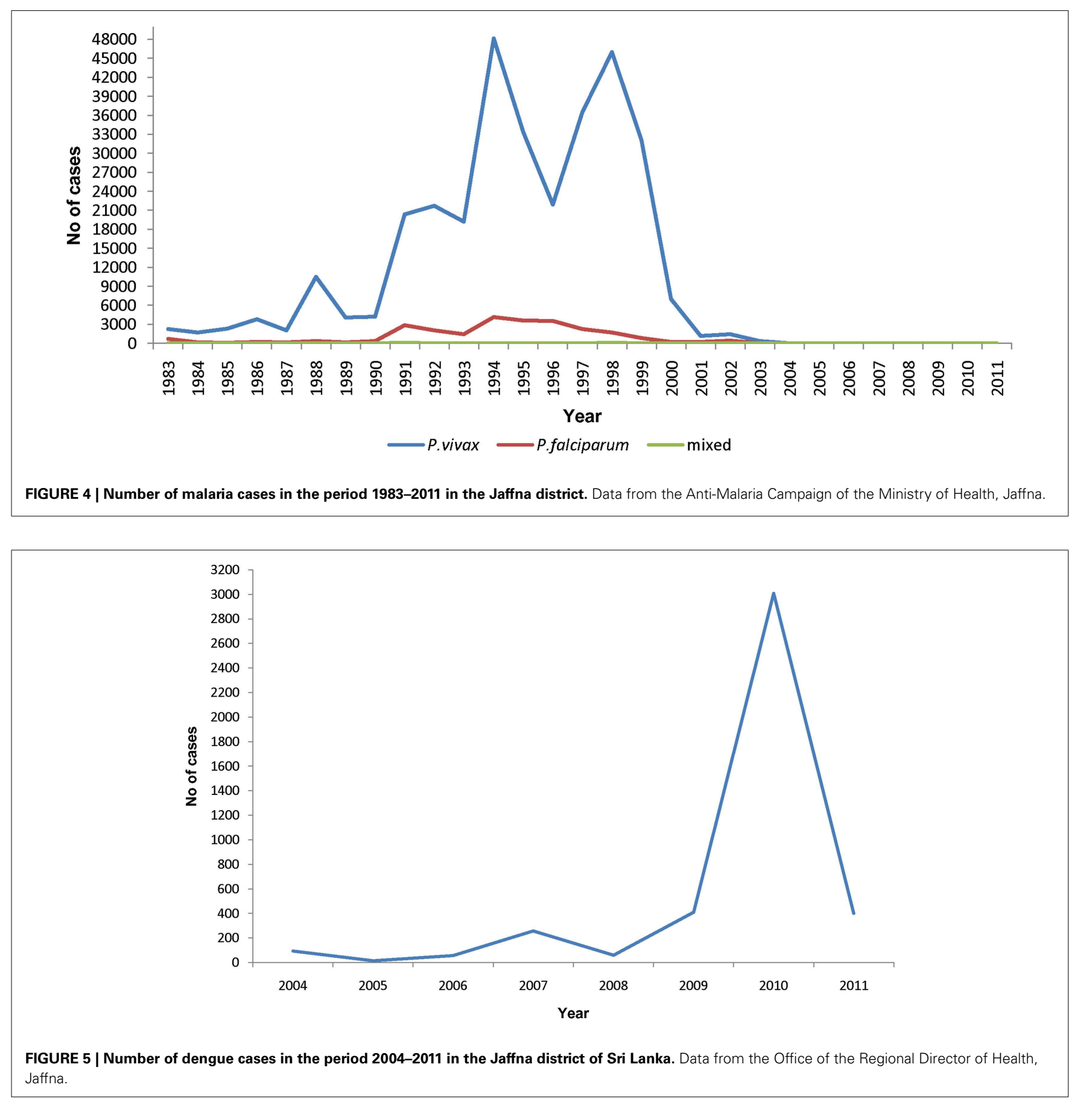

82 of the 162 houses inspected were found to have Aedes larvae (Surendran et al., 2007b). A similar study carried out to assess public perception toward malaria, targeting 157 households living in high risk and low risk areas, showed that knowledge of the involvement of mosquito in malaria was high among all populations (95\%; Kannathasan et al., 2008). Knowledge of preimaginal mosquito development habitats was greater in high risk (90\%) than low risk $(70 \%)$ malarial areas. It may be surmised that disease burden and the public awareness programs have significantly influenced public perceptions on the mode of transmission of chikungunya and malaria. The impacts of the present dengue control measures and public education programs on in Jaffna have not yet been similarly evaluated. Furthermore, the recent findings that malaria and dengue vectors are able to tolerate salinity variations and undergo preimaginal development in brackish waters (Jude et al., 2010; Surendran et al., 2010, 2011; Ramasamy et al., 2011) have yet to lead to the development of appropriate new vector control strategies by health authorities. Specific issues regarding insecticidal control may arise in the context of its application to brackish water larval habitats. Larvicides successfully used in fresh 


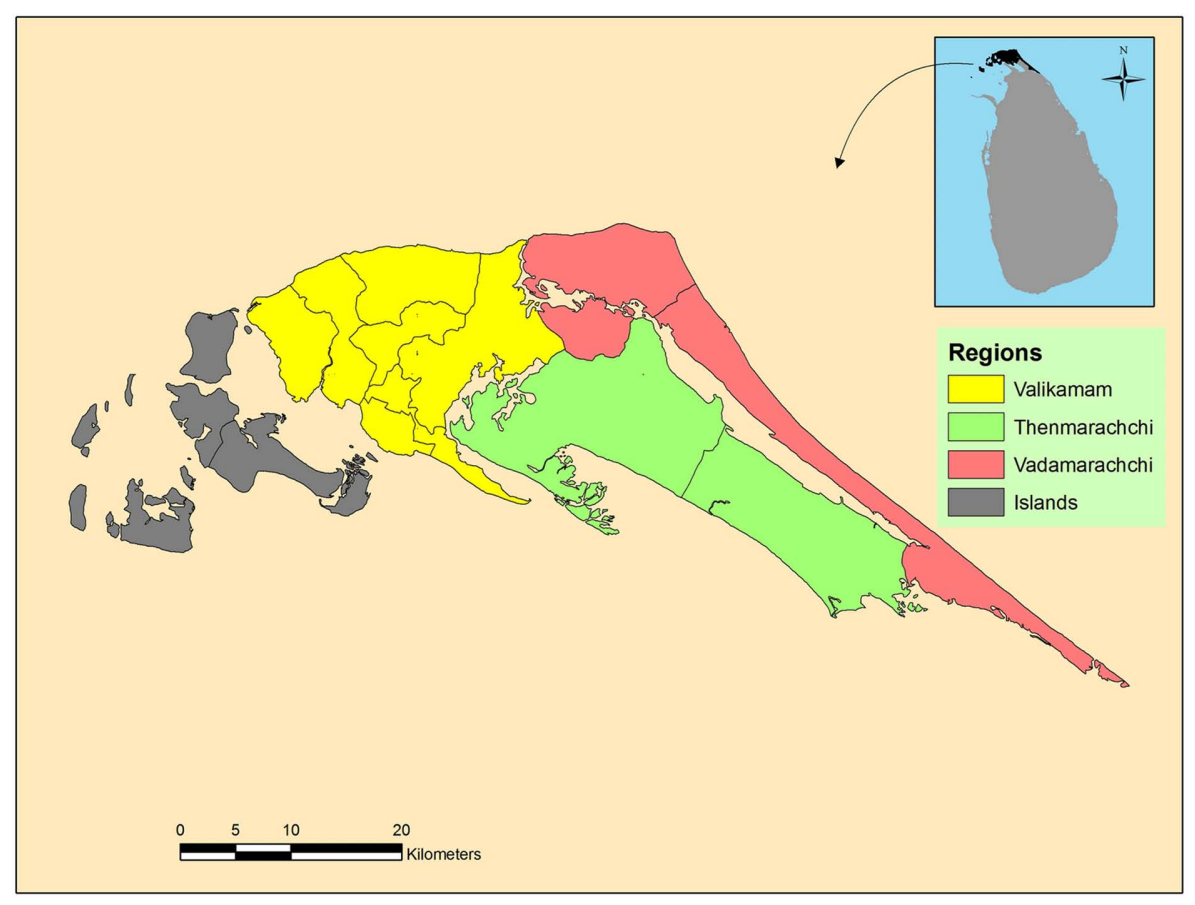

FIGURE 6 | Map of the different administrative divisions in the Jaffna peninsula.

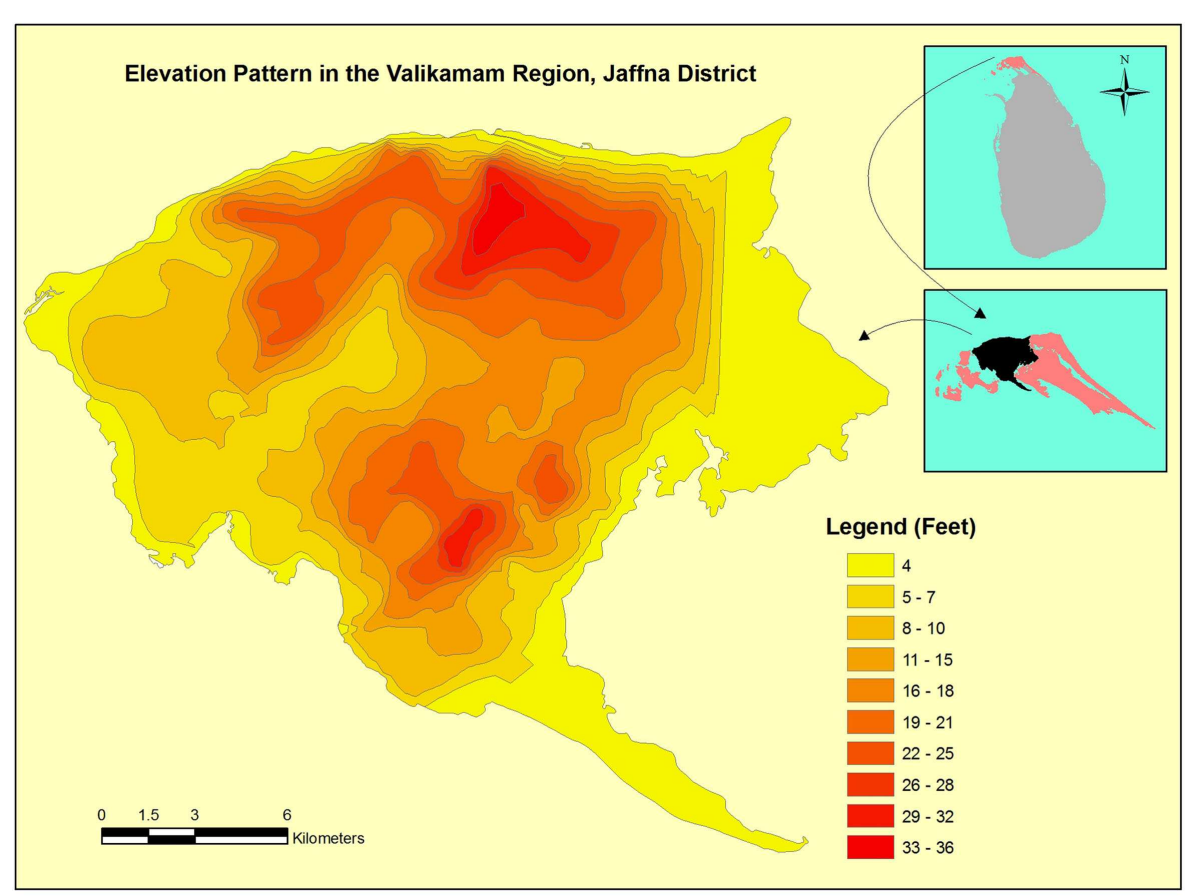

FIGURE 7 | Map showing elevations above mean sea level in the Valikamam division of the Jaffna district.

water habitats may not always have the same efficacy in brackish water. For example, Bacillus thuringiensis a soil dwelling bacterium commonly used in the dengue vector control program in Jaffna, is less effective at salinities in the range of 8-14 ppt against Ae. aegypti larvae (Gobika, S., Tharmatha, T., Jude, P.J., Senthilnanthanan, M., Kannathasan, S., Surendran, S.N. and Ramasamy, R., unpublished 
data). This is relevant because Ae. aegypti and Ae. albopictus larvae were detected in brackish water of up to 15 ppt salinity in coastal zones of Sri Lanka (Ramasamy et al., 2011).

The limited data available in Sri Lanka suggest that the temperature in the country has increased by $0.14^{\circ} \mathrm{C}$ per decade in the period 1930-2000. Rainfall has shown a decreasing trend, with $2 \%$ decrease in Jaffna in this period (Premalal, 2010). Decreasing rainfall is expected to increase the ground water salinization by reducing the rate of recharge with fresh water. The Jaffna peninsula is composed of four administrative divisions (Figure 6) with Valikamam being the most populous. A relief map of Valikamam showing the elevation above mean sea level is presented in Figure 7. This suggests that the predicted $18-59 \mathrm{~cm}(\sim 0.5-$ 2 feet) rise in sea levels by the end of this century (Nicholls et al., 2007; United Nations Intergovernmental Panel on Climate Change, 2007), may markedly increase salinization of inland freshwater aquifers and wells in the peninsula (Food and Agricultural Organisation, 2007). Domestic wells and ponds near the coast will become more brackish. These developments can influence mosquito vector prevalence, distribution and ecology, and promote further adaptation of fresh water vectors to undergo preimaginal development in brackish waters. Such changes will need to be monitored closely by health authorities.

\section{CONCLUSION}

More than half the global population live on land that is $<60 \mathrm{~km}$ from a seashore. Population density in coastal areas is expected to increase from 87 persons per $\mathrm{km}^{2}$ in the year 2000 to 134 persons per $\mathrm{km}^{2}$ in 2050 (United Nations Environment Programme,

\section{REFERENCES}

Alonso, D., Bouma, M. J., and Pascual, M. (2011). Epidemic malaria and warmer temperatures in recent decades in an East African highland. Proc. Biol. Sci. 278, 1661-1669.

Barraud, P. J. (1934). “Diptera Vol. V family Culicidae. Tribes Megarhinini and Culicini," in The Fauna of British India, Including Ceylon and Burma, eds R. B. S. Sewell and P. W. Edwards (London: Taylor and Francis).

Bradley, T. J. (1987). Physiology of osmoregulation in mosquitoes. Annu. Rev. Entomol. 32, 439-462.

Carver, S., Spafford, H., Storey, A., and Weinstein, P. (2009). Colonisation of ephemeral water bodies in the Wheatbelt of Western Australia by assemblages of mosquitoes (Diptera: Culicidae): role of environmental factors, habitat and disturbance. Environ. Entomol. 38, 1585-1594.

Carver, S., Spafford, H., Storey, A., and Weinstein, P. (2010). The roles of predators, competitors and secondary salinisation in structuring mosquito (Diptera: Culicidae) assemblages in ephemeral water bodies in the Wheatbelt of Western Australia. Environ. Entomol. 39, 798-810.

Cavrini, F., Gaiban, P., Pierro, A. M., Rossini, G., Landini, M. P., and Sambri, V. (2009). Chikungunya: an emerging and spreading arthropodborne viral disease. J. Infect. Dev. Ctries. 3, 744-752.

Chan, K. L., Ho, B. C., and Chan, Y. C. (1971). Aedes aegypti (L.) and Aedes albopictus (Skuse) in Singapore City. Bull. World Health Organ. 4, 629-633.

Chaves, L. F., Hashizume, M., Satake, A., and Minakawa, N. (2012). Regime shifts and heterogenous trends in malaria time series from Western Kenyan highlands. Parasitology 139, 14-25.

Chun, L., Telisinghe, L. D., Hossain, M. M., and Ramasamy, R. (2007). Vaccine development against dengue and shigellosis and implications for control of the two diseases in Brunei Darussalam. Brunei Darussalam J. Health 2, 60-71.

Coluzzi, M., and Sabatini, A. (1969). Cytogenetic observations on the salt water species, Anopheles merus and Anopheles melas of the Gambiae complex. Parasitologia 11, 177-187.

2007), and this trend is likely to be particularly pronounced in tropical developing countries where many mosquito-borne diseases are endemic. Therefore growing numbers of people will be placed at risk by an increase in mosquito vector populations in coastal zones. Hence there is an important need to raise awareness among the health authorities and other relevant government sectors, e.g., environmental management, on the health risks associated with mosquito vectors developing in brackish water, particularly in the context of rising sea levels due to global warming. This is relevant not only to the Jaffna peninsula but similar coastal zones of tropical and semi-tropical countries worldwide, where mosquito-borne diseases are endemic. The development of appropriate preventive and mitigating measures will be necessary in local, national, and global levels. More research into salinity-tolerant mosquito vectors, particularly with regard to their changing bionomics is needed to develop better control measures. We propose that the Jaffna peninsula constitutes a useful case study for the impact of global climate change and rising sea levels on mosquito vector populations and disease transmission in tropical coastal zones. A systems-based approach encompassing the effects of different primary climate change parameters and their secondary effects, changing salinity, and other ecological and socio-economic factors on mosquito populations and disease transmission is possible in the Jaffna peninsula.

\section{ACKNOWLEDGMENTS}

We thank S. Raveendran of the Department of Geography, University of Jaffna for the maps in Figures 6 and 7.

Confalonieri, U., Menne, B., Akhtar, R. Ebi, K. L., Hauengue, M., Kovats, R. S., Revich, B., and Woodward, A. (2007). "Human health," in Climate Change 2007: Impacts, Adaptation and Vulnerability. Contribution of Working Group II to the Fourth Assessment Report of the Intergovernmental Panel on Climate Change, eds M. L. Parry, O. F. Canziani, J. P. Palutikof, P. J. van der Linden, and C. E. Hanson (Cambridge: Cambridge University Press), 391-431.

Dambach, P., Sie, A., Lacaux, J. P., Vignolles, C., Machault, V., and Sauerborn, R. (2009). Using high spatial resolution remote sensing for risk mapping of malaria occurrence in the Nouna district, Burkina Faso. Glob. Health Action doi:10.3402/gha.v2i0.2094

Dobson, M. J. (1994). Malaria in England: a geographical and historical perspective. Parassitologia 36, 35-60.

Edwards, H. A. (1982). Free amino acids as regulators of osmotic pressure in aquatic insect larvae. J. Exp. Biol. 101, 153-160.

Eisele, T. P., Keating, J., Swalm, C., Mbogo, C. M., Githeko, A. K., Regens, J. L., Githure, J. I., Andrews,
L., and Beier, J. C. (2003). Linking field-based ecological data with remotely sensed data using a geographic information system in two malaria endemic urban areas of Kenya. Malar. J. 2, 44.

Erickson, S. M., Xi, Z., Mayhew, G. F., Ramirez, J. L., Aliota, M. T., Christensen, B. M., and Dimopoulos, G. (2009). Mosquito infection responses to developing filarial worms. PLoS Negl. Trop. Dis. 3, e529. doi:10.1371/journal.pntd.0000529

Food and Agricultural Organisation. (2007). Seawater Intrusion in Coastal Aquifers - Guidelines for Study, Monitoring and Control. Rome: FAO.

Garrett, M. A., and Bradley, T. J. (1987). Extracellular accumulation of proline, serine and trehalose in the haemolymph of osmoconforming brackish-water mosquitoes. J. Exp. Biol. 129, 231-238.

Geissler, E., and Guillemin, J. (2010). German flooding of the Pontine Marshes in World War II. Politics Life Sci. 29, 2-23.

Gething, P. W., Smith, D. L., Patil, A. P., Tatem, A. J., Snow, R. W., and Hay, S. I. (2010). Climate change and global malaria recession. Nature 465, 342-346. 
Giglioli, G. (1963). Ecological change as a factor in renewed malaria transmission in an eradicated area. Bull. World Health Organ. 29, 131-145.

Githeko, A. K., Lindsay, S. W., Confalonieri, U. E., and Patz, J. A. (2000). Climate change and vector-borne diseases: a regional analysis. Bull. World Health Organ. 78, 1136-1147.

Gunasekaran, K., Jambulingam, P., Srinivasan, R., Sadanandane, C., Doss, P. B., Sabesan, S., Balaraman, K., and Das, P. (2005). Malaria receptivity in the tsunami-hit coastal villages of southern India. Lancet Infect. Dis. 5, 531-532.

Guzman, M. G., and Vazquez, S. (2010). The complexity of antibodydependent enhancement of dengue virus infection. Viruses 2, 2649-2662.

Hales, S., de Wet, N., Maindonald, J., and Woodward, A. (2002). Potential effect of population and climate changes on global distribution of dengue fever: an empirical model. Lancet 360, 830-834.

Halstead, S. B. (2003). Neutralisation and antibody-dependent enhancement of dengue viruses. Adv. Virus Res. 60, 421-467.

Hanley, K. A., Nelson, J. T., Schirtzinger, E. E., Whitehead, S. S., and Hanson, C. T. (2008). Superior infectivity for mosquito vectors contributes to competitive displacement among strains of dengue virus. BMC Ecol. 8 , 1. doi:10.1186/1472-6785-8-1

Hashizume, M., Terao, T., and Minakawa, N. (2009). The Indian Ocean Dipole and malaria risk in the highlands of western Kenya. Proc. Natl. Acad. Sci. U.S.A. 106, 1857-1862.

Hunter, P. R. (2003). Climate change and waterborne and vector-borne disease. J. Appl. Microbiol. 94, 37S46S.

Jardine, A., Lindsay, M. D., Johansen, C. A., Cook, A., and Weinstein, P. (2008). Impact of dryland salinity on population dynamics of vector mosquitoes (Diptera: Culicidae) of Ross River virus in inland areas of southwestern Western Australia. J. Med. Entomol. 45, 1011-1022.

Jude, P. J., Dharshini, S., Vinobaba, M., Surendran, S. N., and Ramasamy, R. (2010). Anopheles culicifacies breeding in brackish waters in Sri Lanka and implications for malaria control. Malar. J. 9, 106.

Kannathasan, S., Antonyrajan, A., Karunaweera, N. D., Anno, S., and Surendran, S. N. (2009). Identification of potential malaria risk areas of Jaffna district, northern Sri
Lanka: A GIS approach. J. National Sci. Found. Sri Lanka 37, 223-225.

Kannathasan, S., Antonyrajan, A., Srikrishnaraj, K. A., Karunaratne, S. H. P. P., Karunaweera, N. D., and Surendran, S. N. (2008). Studies on prevalence of anopheline species and community perception of malaria in Jaffna district, Sri Lanka. J. Vector Borne Dis. 45, 231-239.

Komalamisra, N., Trongtokit, Y., Palakul, K., Prummongkol, S., Samung, Y., Apiwathnasorn, C., Phanpoowong, T., Asavanich, A., and Leemingsawat, S. (2006). Insecticide susceptibility of mosquitoes invading tsunami-affected areas of Thailand. Southeast Asian J. Trop. Med. Public Health 37, 118-122.

Krishnamoorthy, K., Jambulingam, P., Natarajan, R., Shriram, A. N., Das, P. K., and Sehgal, S. C. (2005). Altered environment and risk of malaria outbreak in South Andaman, Andaman \& Nicobar islands, India affected by the tsunami disaster. Malar. J. 4, 32.

Kulatilaka, T. A., and Jayakuru, W. S. (1998). Control of dengue/dengue haemorrhagic fever in Sri Lanka. Dengue Bull. 22, 53-61.

La Ruche, G., Souares, Y., Armengaud, A., Peloux-Petlot, F., Delaunay, P., Desprès, P., Lenglet, A., Jourdain, F., Leparc-Goffart, I., Charlet, F., Ollier, L., Mantey, K., Mollet, T., Fournier, J. P., Torrents, R., Leitmeyer, K., Hilairet, P., Zeller, H., Van Bortel, W., Dejour-Salamanca, D., Grandadam, M., and GastelluEtchegorry, M. (2010). First two autochthonous dengue virus infections in metropolitan France. Euro Surveill. 15, 19676.

Lindsay, S. W., and Birley, M. H. (1996). Climate change and malaria transmission. Ann. Trop. Med. Parasitol. 90, 573-88.

Lindsay, S. W., and Martens, W. J. M. (1998). Malaria in the African highlands: past, present and future. Bull. World Health Organ. 76, 33-45.

MacDonald, G. (1957). The Epidemiology and Control of Malaria. London: Oxford University Press.

McMichael, A. J., Woodruff, R. E., and Hales, S. (2006). Climate change and human health: present and future risks. Lancet 367, 859-869.

Nagarajah, S., Emerson, B. N., Abeykoon, V., and Yogalingam, S. (1988). Water quality of some wells in Jaffna and Kilinochchi with special reference to nitrate pollution. Trop. Agricult. 44, 61-73.

Nicholls, R. J., Wong, P. P., Burkett, V. R., Codignotto, J. O., Hay, J. E., McLean, R. F., Ragoonaden, S., and
Woodroffe, C. D. (2007). "Coastal systems and low-lying areas. Climate Change 2007: impacts, adaptation and vulnerability," in Contribution of Working Group II to the Fourth Assessment Report of the Intergovernmental Panel on Climate Change, eds M. L. Parry, O. F. Canziani, J. P. Palutikof, P. J. van der Linden, and C. E. Hanson (Cambridge: Cambridge University Press), 315-356.

Omumbo, J. A., Lyon, B., Waweru, S. M., Connor, S. J., and Thomson, M. C. (2011). Raised temperatures over the Kericho tea estates: revisiting the climate in the East African highlands malaria debate. Malar. J. 10, 12.

Ooi, E. E., Goh, K. T., and Gubler, D. J. (2006). Dengue prevention and 35 years of vector control in Singapore. Emerging Infect. Dis. 12, 887-893.

Paaijmans, K. P., Read, A. F., and Thomas, M. B. (2009). Understanding the link between malaria risk and climate. Proc. Natl. Acad. Sci. U.S.A 106, 13844-13849.

Peiris, J. S., Premawansa, S., Ranawaka, M. B., Udagama, P. V., Munasinghe, Y. D., Nanayakkara, M. V., Gamage, C. P., Carter, R., David, P. H., and Mendis, K. N. (1988). Monoclonal and polyclonal antibodies both block and enhance transmission of human Plasmodium vivax malaria. Am. J. Trop. Med. Hyg. 39, 26-32

Premalal, K. H. M. S. (2010). “Climate change and the variability in rainfall pattern in Sri Lanka," in Proceedings of the Third National Geographic Conference, Ruhuna, 31.

Rajasooriyar, L. D., Mathavan, V., Dharmagunewardene, H. A., and Nandakumar, V. (2002). "Groundwater quality in the Valigamam region of the Jaffna Peninsula, Sri Lanka," in Sustainable Groundwater Development, Special Publications 193, eds K. M. Hiscock, M. O. Rivett, and R. M. Davison (London: Geological Society), 181-197.

Rajendram, G. F., and Antony, N. R. (1991). Survey of peridomestic mosquito species of Jaffna peninsula in Sri Lanka. Southeast Asian J. Trop. Med. Public Health 22, 637-642.

Ramasamy, M. S., Sands, M., Kay, B. H., Fanning, I. D., Lawrence, G. W., and Ramasamy, R. (1990). Antimosquito antibodies reduce the susceptibility of Aedes aegypti to arbovirus infection. Med. Vet. Entomol. 4, 49-55.

Ramasamy, R. (1998). Molecular basis for evasion of host immunity and pathogenesis in malaria. Biochim. Biophys. Acta 1406, 10-27.
Ramasamy, R., De Alwis, R., Wijesundera, A., and Ramasamy, M. S. (1992a). Malaria transmission in a new irrigation scheme in Sri Lanka the emergence of Anopheles annularis as a major vector. Am. J. Trop. Med. Hyg. 47, 547-553.

Ramasamy, R., Ramasamy, M. S., Wijesundera, D. A., Dewit, I., Wijesundera, A. P., Dewit, I., Ranasinghe, C., Srikrishnaraj, K. A., and Wickremaratne, C. (1992b). High seasonal malaria transmission rates in the intermediate rainfall zone of Sri Lanka. Ann. Trop. Med. Parasitol. 86, 591-600.

Ramasamy, R., and Surendran, S. N. (2011). Possible impact of rising sea levels on vector-borne infectious diseases. BMC Infect. Dis. 11, 18. doi:10.1186/1471-2334-11-18

Ramasamy, R., Surendran, S. N., Jude, P. J., Dharshini, S., and Vinobaba, M. (2011). Larval development of Aedes aegypti and Aedes albopictus in peri-urban brackish water and its implications for transmission of arboviral diseases. PLoS Negl. Trop. Dis. 5, e1369. doi:10.1371/journal.pntd.0001369

Reiter, P. (2001). Climate change and mosquito borne disease. Environ. Health Perspect. 109, 141-161.

Rezza, G., Nicoletti, L., Angelini, R., Romi, R., Finarelli, A. C., Panning, M., Cordioli, P., Fortuna, C., Boros, S., Magurano, F., Silvi, G., Angelini, P., Dottori, M., Ciufolini, M. G., Majori, G. C., Cassone, A., and CHIKV Study Group. (2007). Infection with chikungunya virus in Italy: an outbreak in a temperate region. Lancet 370, 1840-1846.

Rogers, D. J., and Randolph, S. E. (2000). The global spread of malaria in a future warmer world. Science 289 , 1763-1766.

Root, T. L., Price, J. T., Hall, K. R., Schneider, S. H., Rosenzweig, C., and Pounds, J. A. (2003). Fingerprints of global warming on wild animals and plants. Nature 421, 57-60.

Sanchez, L., Vanlerberghe, V., Alfonso, L., Marquetti, M., del, C., Guzmanm, M. G., Bisset, J., and van der Stuyft, P. (2006). Aedes aegypti larval indices and risk of dengue epidemics. Emerging Infec. Dis. 12, 800-806.

Schwartz, O., and Albert, M. L. (2010). Biology and pathogenesis of chikungunya virus. Nat. Rev. Microbiol. 8, 491-500.

Sinka, M. E., Bangs, M. J., Chareonviriyaphap, T., Patil, A. P., Temperley, W. H., Gething, P. W., Elyazar, I. R., Kabaria, C. W., Harbach, R. 
E., and Hay, S. I. (2011). The dominant Anopheles vectors of human malaria in the Asia-Pacific region: occurrence data, distribution maps and bionomic précis. Parasit. Vectors 4,89 .

Smith, K. E., Van Ekeris, L. A., Okech, B. A., Harvey, W. R., and Linser, P. J. (2008). Larval anopheline mosquito recta exhibit a dramatic change in localization patterns of ion transport proteins in response to shifting salinity: a comparison between anopheline and culicine larvae. J. Exp. Biol. 211, 3067-3076.

Surendran, S. N., Jude, P. J., and Ramasamy, R. (2011). Variations in salinity tolerance of malaria vectors of the Anopheles subpictus complex in Sri Lanka and the implications for malaria transmission. Parasit. Vectors $4,117$.

Surendran, S. N., Kajatheepan, A., Sanjeevkumar, K. F. A., and Jude, P. J. (2007a). Seasonality and insecticide susceptibility of dengue vectors: an ovitrap based survey in a residential area in northern Sri Lanka. Southeast Asian J. Trop. Med. Public Health 38, 276-282.

Surendran, S. N., Kannathasan, S., Kajatheepan, A., and Jude, P. J. (2007b). Chikungunya-type fever outbreak: some aspects related to this new epidemic in Jaffna district, northern Sri Lanka. Trop. Med. Health 35, 249-252.

Surendran, S. N., and Ramasamy, R. (2010). The Anopheles culicifacies and Anopheles subpictus species complexes in Sri Lanka and their implications for malaria control in the country. J. Trop. Med. Hyg. 38, $1-11$.

Surendran, S. N., Singh, O. P., Jude, P. J., and Ramasamy, R. (2010). Genetic evidence for malaria vectors of the Anopheles sundaicus complex in Sri Lanka with morphological characteristics attributed to Anopheles subpictus species B. Malar. J. 9, 343.

Sutherst, R. W. (2004). Global change and human vulnerability to vector borne diseases. Clin. Microbiol. Rev. 17, 136-173.

Takken, W., Geene, R., Adam, W., Jetten, H., and van der Velden, J. A. (2002). Distribution and dynamics of larval populations of Anopheles messae and an atroparvus in the delta of of the rivers Rhine and Meuse, The Netherlands. Ambio 31, 212-218.

Timmermann, A., Oberhuber, J., Bacher, A., Esch, M., Latif, M., and Roeckner, E. (1999). Increased El Niño frequency in a climate model forced by future greenhouse warming. Nature 398, 694-697.

Tipayamongkholgul, M., Fang, C. T., Klinchan, S., Liu, C. M., and King, C. C. (2009). Effects of the El Niño-Southern Oscillation on dengue epidemics in Thailand, 1996-2005. BMC Public Health 9, 422. doi:10.1186/1471-2458-9-422

Trung, H. D., Van Bortel, W., Sochantha, T., Keokenchanh, K., Quang, N. T., Cong, L. D., and Coosemans, M. (2004). Malaria transmission and major malaria vectors in different geographical areas of Southeast Asia. Trop. Med. Int. Health 9, 230-237.
United Nations Environment Programme. (2007). Global Programme of Action for the Protection of the Marine Environment from Landbased Activities: Physical Alteration and Destruction of Habitats. Nairobi: UNEP.

United Nations Intergovernmental Panel on Climate Change. (2007). IPCC Fourth Assessment Report: Climate Change 2007. Geneva: IPCC.

van Schie, C., Spafford, H., Carver, S., and Weinstein, P. (2009). Salinity tolerance of Aedes camptorhynchus (Diptera: Culicidae) from two regions in southwestern Australia. Aust. J. Entomol. 48, 293-299.

Walter Reed Biosystematics Unit. (2011). Keys to Medically Important Mosquito Species. Silver Spring, MA: Smithsonian Institution.

Wayant, N. M., Maldenado, D., De Arias, A. R., Cousino, D., and Goodin, D. G. (2010). Correlation between normalized difference vegetation index and malaria in a subtropical rain forest undergoing rapid anthropogenic alteration. Geospat. Health 4, 179-190.

Weaver, S. C., and Reisen, W. K. (2010). Present and future arboviral threats. Antiviral Res. 85, 328-345.

World Health Organization. (2009a). Fact Sheet No 117 Dengue and Dengue Haemorrhagic Fever. Geneve: World Health Organization.

World Health Organization. (2009b). Dengue Guidelines for Diagnosis, Treatment, Prevention and Control. WHO/HTM/NTD/DEN/2009.1.

Available at: http://whqlibdoc.who. int/publications/2009/9789241547 871_eng.pdf [accessed July 12, 2011].

World Health Organization. (2010a). Fact Sheet No 94 Malaria. Genève: World Health Organization.

World Health Organization. (2010b). Fact Sheet No 102 Lymphatic Filariasis. Geneve: World Health Organization.

World Health Organization. (2011). World Malaria Report 2010. Geneve: World Health Organization.

Conflict of Interest Statement: The authors declare that the research was conducted in the absence of any commercial or financial relationships that could be construed as a potential conflict of interest.

Received: 26 January 2012; accepted: 22 May 2012; published online: 19 June 2012.

Citation: Ramasamy $R$ and Surendran SN (2012) Global climate change and its potential impact on disease transmission by salinity-tolerant mosquito vectors in coastal zones. Front. Physio. 3:198. doi: 10.3389/fphys.2012.00198

This article was submitted to Frontiers in Systems Biology, a specialty of Frontiers in Physiology.

Copyright $(2012$ Ramasamy and Surendran. This is an open-access article distributed under the terms of the Creative Commons Attribution Non Commercial License, which permits noncommercial use, distribution, and reproduction in other forums, provided the original authors and source are credited. 